\title{
Strategic Incentive Systems For Open Innovation
}

\author{
Dirk Schneckenberg, ESC Rennes School of Business, France
}

\begin{abstract}
Our paper presents a cross-sectional study of incentive systems for open innovation practices. Organisations face the challenge to design and implement strategic incentive systems which reward active contributions of individuals to open innovation practices. We refer to contributions from psychology and economics to develop a framework for organisational incentive systems. We have conducted semi-structured interviews with 10 experts in Germany and the Netherlands. The experts work in firms which are both international top players and open innovation pioneers in their respective industries. The results show that all organisations in the sample develop incentives for open innovation. The key strategic function of incentive systems is to open mind-sets of the workforce and to overcome mental barriers of the 'not invented here' syndrome. Immaterial and in particular task content incentives have been judged to have a more efficient long-term impact than material incentives. While experts have emphasised the importance of aligning incentives systems to open innovation strategies, in practice many incentive approaches still remain patchwork and lack a clear strategic focus.
\end{abstract}

Keywords: Open Innovation Incentives; Strategic Incentive Systems; Open Innovation Practices

\section{INTRODUCTION}

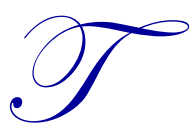

he concept of open innovation has become increasingly popular in both innovation management research and practice (Gassman et al., 2010; Huizingh, 2010). The work of Chesbrough, (2003, 2007) which identifies inbound and outbound knowledge flows as main drivers for faster innovation and new market opportunities, serves as well accepted conceptual basis for the open innovation community. But while the rapid growth of publications mirrors the dynamics of open innovation as topic for academic research, we still need to better understand a range of issues for an efficient application of the concept in business practice (Lichtenthaler, 2011; Piller \& Ihl, 2009).

While research on corporate incentive systems has a long-standing tradition in psychological and human resources literature (Gagne \& Deci, 2005; Ryan \& Deci, 2000; Amabile, 1993), relatively little is known on the design and implementation of incentives in the context of open innovation. One problem that organisations face against this background is the design and implementation of strategic incentive systems which reward engagement of internal employees and external collaborators in open innovation practices. Setting the right incentives turns out to be a key challenge for firms which aim to move their corporate culture towards the open innovation paradigm (Alexy et al., 2013; Enkel et al., 2009).

We therefore investigate in this study the topic of adequate incentives that help to reward active engagement for open innovation practices of firms. New insights into this question are relevant from theoretical perspective, as they will complement existing knowledge about open innovation processes with a specific focus on the role of motivational drivers for internal and external contributors. From managerial perspective, insights into this question can help firms to get a better understanding of the different types of incentives that foster open innovation practices and how they can integrate these incentives into a more coherent strategic framework to support their respective open innovation initiatives. 


\section{BACKGROUND}

There is not a lot of previous research on the use of incentive systems to foster open innovation practices. Gassmann et al. (2010) relate incentives to the wider perspective of developing open innovation cultures and define them as measures with directly influence open innovation practices, such as knowledge networking and the cocreation of innovative products and services. Ling \& Nasurdin (2010) have empirically verified a range of potential positive effects for the implementation of innovative incentives in corporate human resource management practices on the innovation behaviour of firms in dynamic environments. However, their research is restricted to one specific industrial context and does not explicitly focus on open innovation practices. Von Hippel \& von Krogh (2006) argue in their private-collective model of innovation incentives that free revealing is a key process in open innovation. They have observed that the revealing of proprietary information and knowledge in innovation projects, which brings private and collective participants together, leads to mutual gains for all involved parties. Garriga et al. (2012) build on the private-collective model and emphasise that right incentives are one precondition for participants to contribute and share knowledge in open innovation projects. Amaral et al. (2010) found that close alignment of incentives systems to open innovation strategies is a precondition for fostering relationships between firms and their peripheries by paying attention to the motivation of both internal and external contributors.

From point of view of corporate strategies, incentives systems can be seen as measures that are designed to align relationships and promote knowledge sharing between interacting organisational units for competitive advantage Finch (2011) states that organisational measures, which intend to change the innovation attitude of decision-making managers, represent one important component for the innovation capacity of firms. With the rise of open innovation as new paradigm that affects business strategies, new actors and relationships appear which question traditional positions and interactions between firms and their surroundings. In consequence, organisations face challenging questions about motivational drivers for open innovation engagement: How to incentivise internal employees and external stakeholders for constantly seeking help where core competence exists? How to design and implement incentive structures that generate the desired open innovation practices? Does a strategic focus for open innovation incentives exist?

We refer to contributions from psychology and economics as most important base disciplines to develop a conceptual basis for organisational incentive systems (Merchant et al., 2003), and conduct expert interviews to explore their current development and use in business. Clark \& Wilson (1961) define incentive systems in their prominent article as a set of measures which regulate the internal activity of organisations. Incentive systems provide tangible or intangible incentives to motivate active contributions of individuals in organisational tasks. Pharr et al. (2011) present in their work a recent overview of different (monetary and non-monetary) incentive options and their assumed effectiveness on desired behavioural changes in target groups. We build in our study on these insights and rely in particular on the incentive systems model of Steiner \& Ritz (2002) to collect and categorise the empirical evidence. Steiner \& Ritz separate extrinsic and intrinsic motivation and relate material (direct and indirect financial) and immaterial (social and organisational) incentives to extrinsic motivation, while the work itself (task content) is linked to intrinsic motivation.

\section{RESEARCH QUESTIONS} practices?

The key research question of this paper is: How can strategic incentive systems foster open innovation

Three investigative questions operationalise the central research question for the data collection and analysis (Wengraf, 2004):

1. Which impact have material incentives on open innovation practices?

2. Which impact have immaterial incentives on open innovation practices?

3. Which impact has the work itself on open innovation practices? 


\section{RESEARCH DESIGN AND DATA COLLECTION}

As the previous section shows, the design and impact of incentive systems on open innovation practices presents an understudied area of potentially high theoretical and practical relevance. The use of specific open innovation incentives have rarely been investigated or conceptualized. As this topic lacks prior theoretical work, we have employed a grounded theory approach as appropriate inductive research design (Miles et al., 2013; Glaser \& Strauss, 1967). To comply with the purpose of our study, which is to investigate the role of formal and informal corporate incentives to foster open innovation practices, we have used the expert interviews method where the researcher purposely chooses well-informed respondents to understand an emergent and so far ill-defined phenomenon in depth (Patton, 2001). We have made a judgement sample, which is the purposive selection of recognised experts in the field, to assure excellent subject-matter knowledge in the interviews (Maxwell, 2005). The main purpose of expert interviews is to learn which issues are of central importance to develop a better understanding of emergent phenomena (Patton, 2001).

The experts should have deep insights into the area of interest so that they are able to present a comprehensive and precise account of emerging practices in the concrete field of action. Consequently, we have identified and contacted corporate experts which combine a comprehensive knowledge on open innovation with a functional responsibility to set incentive structures within their companies. To identify these experts, we have evaluated lists of keynote speakers on open innovation themes in recent international business conferences and contacted promising candidates with a request to participate in the study. We have been able to conduct 10 expert interviews in Germany, Austria and the Netherlands. All experts work in firms which are both international top players and open innovation pioneers in their respective industries. The firms in the interview sample operate in the following industry sectors: IT consulting and services, health technologies, urban infrastructure solutions, energy, pharmaceuticals and chemicals, software development, telecommunication, home and personal care products, business appliances, and mechanical components manufacturing. Table 1 identifies the respondents of the crosssectional sample, their role at work and the role of their companies in the respective industries.

Table 1: Interview Respondents

\begin{tabular}{lcc}
\hline \multicolumn{1}{c}{ Respondent } & Role & Company Role in Industry \\
\hline Respondent A & Open Innovation Specialist & Mechanical Components Manufacturing \\
Respondent B & Alliance Manager & Health Technologies \\
Respondent C & Head of Research & Personal Care Products \\
Respondent D & Innovation Manager & IT Consulting and Services \\
Respondent E & Head Open Innovation and Technology Scouting & Telecommunication \\
Respondent F & Research Development Director & Chemical Business Appliances \\
Respondent G & Business Development Director & IT Services and Solutions \\
Respondent I & Business Development Director & Electronics \\
Respondent J & Open Innovation Specialist & Industrial and Healthcare Equipment Provider \\
Respondent K & Business Development Specialist & IT Content Provider \\
\hline
\end{tabular}

We have used semi-structured interviews to collect the data. Semi-structured interviews allow to search for rich in-depth insights of respondents and to provide at the same time sufficient structure for a comparison of the main issues raised (Maxwell, 2005). We have developed a questionnaire guide which we sent to the interviewees in advance so that they could prepare for the main themes to be discussed. The guideline consists of six sections: (1) personal information; (2) general use of open innovation incentives; (3-5) strategic importance and impact of material incentives, immaterial incentives, and task content incentives; and (6) summary. The structure of the guideline assures the collection of essential information that fit the main incentive setting categories for open innovation practices, and it leaves at the same time sufficient leeway and flexibility for respondents to add exploratory stories and critical side-reflections on the subject (Maxwell, 2005; Yin, 2003).

The semi-open interview design fits well to the intention of our study to gain valuable insights into the role of incentive systems for open innovation. We have asked the experts in the interviews to describe, analyse and reflect on their insights related to open innovation incentives. The average time frame per interview has been approximately 90 minutes. Some experts have in addition provided documents to give complementary information on the incentives strategies of their firms. This documentation comprises internal strategy papers and reports, 
conference presentations, and archival records from open innovation project teams. After 10 interviews we decided to not extend the sample size further, as the patterns and processes for incentive systems in the investigated companies have shown a sufficient level of saturation and convergence (Bryman \& Bell, 2007; Golafshani, 2003).

We have analysed the collected data with the pattern recognition technique, which consists of identifying archetypes and shared frames that are comparable across the different data sources (Yin, 2003; Patton, 2001). The audio streams of the interviews have been recorded, transcribed and translated into English. We have coded and categorised the key patterns of the interview contents into the three dimensions material, immaterial and task content incentives. We have complemented the interview data with a content analysis of the secondary data sources. In a final step we have conceptualised the main findings and summarised strengths and weaknesses of different incentive measures in current open innovation practices.

\section{FINDINGS}

The findings present how the experts evaluate both the importance and the appropriateness of organisational incentive systems for open innovation practices.

The three investigative questions of the study deal with the importance of material, immaterial and task content incentives. The interview data shows that all firms provide specific incentives in all three categories. We have in addition found a great variety of incentive settings in the sample, as different open innovation tools require different types of incentives. We have categorised the detailed incentives with an additional distinction of focus in either internal employees or external collaborators as participants of open innovation practices.

\section{Material Incentives}

Material incentives for internal employees include rewards for open innovation achievement in traditional performance measurement and ideation bonuses. Some experts emphasise however that open innovation is a means to reach the goal of more efficient innovation and that monetary rewards could lead to misleading behaviour that distorts ideation markets.

"In Open Innovation environments, the intrinsic push must be there. If you would support this with awards, just a limited amount of persons will receive awards and this would definitely harm the exchange of thoughts." (Respondent G)

Most experts agreed that employee recognition is a more powerful incentive than bonus payments, as clearly emphasised in the following response:

"Generally, immaterial incentives are much more important than financial ones. If we give awards, the whole technology team will be presented in front of the community, and I think this driver lasts longer than a one time-cash payment. Here, especially the recognition of employees is deeply integrated." (Respondent A)

Recognition leads more probably to a sustainable motivation of employees to contribute to open innovation practices. It has in addition an indirect positive impact on annual salary renegotiations, and salary increases are again more sustainable than one-time bonus payments.

Material incentives for external collaborators include financial support, contractual compensations, coverage of material expenses and access to infrastructure and resources of the lead firm.

"In universities, the interests usually focus on receiving third-party-payments. Furthermore, you pay for external employees and resources that partners provide for joint $R \& D$ projects." (Respondent A)

\section{Immaterial Incentives}

Immaterial incentives for internal employees include access to decision makers, options for international networking, higher visibility of personal profiles in the corporate landscape, acquisition of high-level knowledge 
during networking processes in open innovation projects, and positive collaboration effects like socialisation and building new ties. Experts evaluated immaterial incentives as strong drivers for the change of corporate cultures towards the open innovation paradigm, as indicated in the response below:

"Employee recognition lasts longer than a monetary cash distribution, and the immaterial incentive is much more important than the material one - because if you get invited in front of the board where you can present your idea, this is something which you cannot buy with 1000€." (Respondent J)

Immaterial incentives for external collaborators include access to top players in the industry sector, positive reputation and collaboration effects, and adding value to the brand image of collaborators, as expressed in the following statement.

"There are actual two currencies that are incorporated in partnerships: the first on is money and the second one consists of reputation and intellectual property. Externals like to work with us because we have a very good reputation and knowledge base." (Respondent D)

\section{Task Content Incentives}

Task content incentives for internal employees include more flexible time allocation for research ideas and taking part in expert conversations on hot innovation topics. Several experts have also mentioned personal learning and development in complex and novel open innovation projects as a tool with potential for a wider proliferation in incentive systems.

"If somebody has a superb performance, we are trying to further develop this person by assigning challenging and interesting projects." (Respondent B)

Task content incentives for external collaborators include gaining access to high-value intellectual property and participating in cutting-edge research projects.

"Scientific expertise is the leading task-content incentive for external scientists - first of all, we have to be interesting for partners from a scientific standpoint. They can do things in research and accomplish projects that cannot be done without us. Secondly, scientists gain an appreciation of their personal research profiles and reach a position to be on par with us." (Respondent B)

After identifying the main incentives and their perceived importance, we have subsequently asked the experts to evaluate the appropriateness of the different tools in their incentive systems. As already indicated above, there is a general agreement in the sample of respondents that monetary incentives do not have a long-term positive effect on desired open innovation behaviour. Knowledge sharing processes in the task content dimension are seen on the other hand as a key incentive with high potential to sustainably foster open innovation practices. In particular social reward systems and employee recognition foster knowledge sharing behaviour.

"We are deploying different social reward systems for internal and for external collaborators in open innovation projects. The systems rely on collaborative IT platforms to connect people and make their expertise and reputation in networks visible." (Respondent D)

We can distinct in the interview data between first vs. second tier incentives. While first-tier incentives, like direct bonus payments for ideation activities, are easy to implement, second-tier incentives promise to be more efficient for sustainably motivating internal and external contributions to open innovation practices. Indirect incentives include for example more transparency of decisions and work flows, which leads to personal and organisational efficiency gains; socialisation processes in open innovation contexts that foster open mind-sets and connectedness; improved business results through out-licensing non-strategic intellectual property in open innovation practices; and inclusion of contributors in local technology hubs.

A number of challenges for developing strategic incentive systems have come up in the interviews. As incentive strategies are tools to influence corporate culture, they are context-dependent. We have observed different 
incentive approaches for different corporate cultures in the sample firms. Another question has been if firms should incentivise more work behaviours, or if they should incentivise work behaviours in a different way. Several experts pointed out that the development of open innovation culture and practices necessarily requires changes in traditional incentive systems. Experts also said that incentives have to be tailored and linked to particular open innovation practices.

"I think we have to improve our incentives policy, but compared to our competitors we should count to the better ones. Still, the task of further improvement exists. I think many open innovation issues are unique features right now and have to be fostered by respective incentives as well." (Respondent $\mathrm{K}$ )

This final observation is most likely at the same time the most complex challenge that open innovation evangelists face within their organisations when they try to develop and implement specific incentives. What we have seen in the reflected practice of the interview experts is the common dilemma that incentive approaches for open innovation practices remain largely patchwork and lack a clear strategic focus.

To summarize the results of the inductive study, we can conclude that the interviewed experts perceived open innovation as an important strategic framework to build future competitive capabilities of their companies. Related to this position, the topic of incentive systems is perceived in the interviews as a strategic issue that should be addressed by a combination of measures to drive open innovation practices. However, none of the experts has been able to present a comprehensive and strategically aligned framework of specific and measurable objectives for the development and implementation of corporate incentive systems for open innovation practices. What the majority of experts did present was a rather loosely defined range of incentives to foster intra-firm and inter-firm open innovation activities. Overall, we found in our sample that task content and immaterial incentives are preferred when compared to material incentives. Furthermore, the overall tendency of the experts has been to judge intrinsic incentives, which rely primarily on interesting task content, to be slightly more important when compared to immaterial incentives, which rely primarily on social recognition factors. Work task as incentives are thus perceived to have the most efficient and sustainable positive impact on desired open innovation practices.

\section{CONCLUSIONS}

In this paper, we have explored through an inductive study the emergent topic of incentive systems for open innovation practices in terms of their importance and appropriateness. We summarize the main conclusions in three points. First, our study empirically confirms and adds to the theoretical viewpoint in the literature that incentive systems are one important organisational measure to develop open innovation cultures (Gassmann et al., 2010; Huizingh, 2010). The interviewed experts assign a high importance to incentive systems, which they see as a strategic instrument to foster open innovation practices. The key strategic function of incentive systems is to open mind-sets of the workforce and to overcome the mental barriers of the 'not invented here' syndrome.

Second, the data underlines the argument that a good balance of right incentives is a precondition for participants to contribute in open innovation practices. To give an indication of the right mix, we can make a ranking which is based on the experts' views on the perceived importance and appropriateness of the three incentive system categories. The task content has been overall identified as incentive tool with the highest impact on desirable behaviour of open innovation participants. This tool is followed by immaterial incentives, and material incentives are evaluated with the lowest impact. In terms of sustainability of the impact, material incentives can be used in the short term to foster selected open innovation practices that firms urgently need. Immaterial and task content incentives help in the long term to build up holistic open innovation cultures.

What we have not found is a coherent differentiation and strategic alignment of incentives systems to open innovation strategies of firms. This is surprising, as recent studies (Amaral et al., 2010) stress the importance of alignment, and as our sample has included leading competitors and open innovation pioneers in their respective industries. The interviews indicate a dichotomy between perceived importance of incentive setting for open innovation and incentive systems in business reality. Most experts make a clear distinction between traditional and open innovation related incentive systems, as different desired work behaviours require different organisational incentives. However, these two perspectives do not lead to a separate set of open innovation incentives in business 
practice. Most firms rather add specific measures which aim to foster open innovation practices to their established incentive systems.

\section{IMPLICATIONS FOR PRACTICE AND FUTURE RESEARCH}

Based on the main findings of our explorative study, the first managerial recommendation is to set a focus on whole open innovation strategy instead of narrowing attention down to specific incentives for specific practices that are just added to existing incentive systems. Ideally, firms could assign a dedicated open innovation team that drives change efforts at a deeper level, creates awareness and tailors incentives for specific open innovation practices in the organisational culture. A viable path for organisations to innovate their innovation management is follow the 'think big, start small' approach and to incrementally scale up pilot incentives from group to corporate level.

We next encourage executive decision makers to integrate open innovation into corporate strategies. Strategic alignment is essential for identifying, incentivising and measuring progress in process implementation and long-term achievement of open innovation goals. Alignment is also the basis for developing sustainable incentive systems which foster open innovation practices.

Finally, we argue that organisations should push further towards implementing dedicated incentive systems for open innovation. This way they would make a clear point that a fundamental change is desired to move the corporate culture towards the open innovation paradigm. Incentives, which are unambiguously defined to support open innovation, better fit their purpose and make the new strategic focus explicit within and beyond corporate boundaries. Dedicated incentives have a higher probability to help firms reaping the benefits of crowdsourcing and collective intelligence projects for corporate innovation.

Feeding back into the research field, we perceive open innovation from incentives perspective as a challenge that links to the field of organisational learning (Alexy et al., 2013; Lichtenthaler, 2011). A long-term incremental learning process is required to move open innovation practices into the heart of organisational culture. We found that there is still a considerable lack of awareness of open innovation, in particular at operational business level. The predominant incentivising approach that we found is to create patchwork systems which rather add an open innovation touch to traditional incentive settings instead of rethinking them or setting up dedicated systems. These very incremental changes in incentive systems mirror that moving open innovation from conceptual model to routinized business practice still takes a lot time and commitment. More research on the cultural dimension is needed to help unlocking the full potential of open innovation in corporate practice.

\section{AUTHOR INFORMATION}

Dr. Dirk Schneckenberg, Associate Professor Strategy, ESC Rennes School of Business, 2 rue Robert d'Arbrissel CS 76522, 35065 Rennes Cedex, France. E-mail: dirk.schneckenberg@esc-rennes.fr

\section{REFERENCES}

1. Alexy, O., George, G., \& Salter, A. J. (2013). Cui bono? The selective revealing of knowledge and its implications for innovative activity. Academy of Management Review, 38(2), 270-291.

2. Amabile, T. M. (1993). Motivational synergy: Toward new conceptualizations of intrinsic and extrinsic motivation in the workplace. Human Resource Management Review, 3(3), 185-201.

3. Amaral, J., Anderson, E.G., \& Parker, G.P. (2010). Putting it together: How to succeed in distributed product development. MIT Sloan Management Review, 52(2), 50-58.

4. Bryman, A., \& Bell, E. (2007). Business research methods (2nd Edition). Oxford University Press.

5. Chesbrough, H.W. (2003). Open innovation: The new imperative for creating and profiting from technology. Boston: Harvard Business School Press.

6. Chesbrough, H. W. (2007). Why companies should have open business models. MIT Sloan Management Review, 48(2), 22-28. 
7. Clark, P. B., \& Wilson, J.Q. (1961). Incentive systems: a theory of organizations. Administrative Science Quarterly, 6, 129-166.

8. Enkel, E., Gassmann, O., \& Chesbrough, H. (2009). Open R\&D and open innovation: exploring the phenomenon. R\&D Management, 39(4), 311-316.

9. Fey, C. F., \& Furu, P. (2008). Top management incentive compensation and knowledge sharing in multinational corporations. Strategic Management Journal, 29(12), 130-1323.

10. Finch, J. E. (2011). R\&D Expenditures As resource buffers: Managing the capacity to innovate. Journal of Applied Business Research, 7(4), 98-103.

11. Gagne, M., \& Deci, E. L. (2005). Self-determination theory and work motivation. Journal of Organizational Behavior, 26(4), 331-362.

12. Garriga, H., Aksuyek, E., von Krogh, G., \& Hacklin, F. (2012). What social preferences matter in privatecollective innovation? Behavioral game theory in collective action. Technology Analysis \& Strategic Management, 24(2), 113-127.

13. Gassmann, O., Enkel, E., \& Chesbrough, H.W. (2010). The future of open innovation. R\&D Management, 40(3), 213-221.

14. Glaser, B., \& Strauss, A. (1967). The discovery of grounded theory. London: Weidenfeld and Nicholson.

15. Golafshani, N. (2003). Understanding reliability and validity in qualitative research. The Qualitative Report, 8, 597-607.

16. Huizingh, E. K. R. E. (2010). Open innovation: State of the art and future perspectives. Technovation, 31, 2-9.

17. Lichtenthaler, U. (2011). Open innovation: Past research, current debates, and future directions. Academy of Management Perspectives, 25(1), 75-93.

18. Ling, T. C., \& Nasurdin, A. M. (2010). Human resource management practices and organizational innovation: An empirical study in Malaysia. Journal of Applied Business Research, 26(4), 105-116.

19. Maxwell, J.A. (2005). Qualitative research design: An interactive approach (2nd ed.). Applied Social Research Methods Series, Vol. 41, Thousand Oaks, CA: Sage Publications.

20. Merchant, K.A., Van der Stede, W.A., \& Zheng, L. (2003). Disciplinary constraints on the advancement of knowledge: the case of organizational incentive systems. Accounting, Organizations and Society, 28, 251286.

21. Miles, M. B., Huberman, A. M., \& Saldaña, J. (2013). Qualitative data analysis: A methods sourcebook. Thousand Oaks: Sage Publications.

22. Myers, M. D., \& Newman, M. (2007). The qualitative interview in IS research: Examining the craft. Information and Organization, 17(1), 2-26.

23. Patton, M.Q. (2001). Qualitative research and evaluation methods (2nd ed.). CA: SAGE Publications.

24. Pharr, S. W., Stuefen, R. M., \& Wilber, M. (2011). The effects of non-monetary incentives upon survey refusal tendencies of the affluent consumer population. Journal of Applied Business Research, 6(3), 88-97.

25. Piller, F. \& Ihl, C. 2009. Open innovation with customers. Foundations, Competences and International Trends. Trend Study within the BMBF Project "International Monitoring”. RWTH Aachen University.

26. Ryan, R. M., \& Deci, E. L. 2000. Intrinsic and extrinsic motivations: Classic definitions and new directions. Contemporary Educational Psychology, 25(1), 54-67.

27. Steiner, R., \& Ritz, A. (2002): Beurteilung und Entlöhnung von Lehrpersonen. In: Effektive Schulführung, hrsg. v. Norbert Thom, Adrian Ritz und Reto Steiner. Bern, Stuttgart, Wien 2002, pp. 207-237.

28. Von Hippel, E., \& von Krogh, G. (2006). Free revealing and the private-collective model of innovation incentives. $R \& D$ Management, 36(3), 295-306.

29. Wengraf, T. (2004). Qualitative research interviewing. Thousand Oaks, CA: Sage Publications.

30. Yin, R. K. (2003). Case study research. design and methods. Thousand Oaks, CA: Sage Publications. 